Saudi Journal of Oral and Dental Research

Abbreviated Key Title: Saudi J Oral Dent Res

ISSN 2518-1300 (Print) |ISSN 2518-1297 (Online)

Scholars Middle East Publishers, Dubai, United Arab Emirates

Journal homepage: https://saudijournals.com/sjodr

\title{
Attitude and Knowledge of the Dental Doctors about the Bone Loss Management in Orthodontic Patients in Jizan, Saudi Arabia
}

Roaa Tobaigy", Fatimah Alhuraysi, Najwa Ali Anab, Fatima Sultana

Department of Dentistry, Jizan, Saudi Arabia

DOI: $10.36348 /$ sjodr.2020.v05i01.013

| Received: 02.01.2020 | Accepted: 17.01.2020 | Published: 30.01.2020

*Corresponding author: Roaa Tobaigy

\section{Abstract}

The orthodontic treatment includes the use of varied dental devices like headgear, braces and plates to enhance the beauty of smile, improves the speech and the biting ability. The treatment that causes the movement of the teeth and also results in decrease in bone density of the teeth. The loss of bone around the tooth may be temporary or permanent. A proper plan need to be considered before orthodontically treating a a patient to reduce the alveolar bone loss. The survey included questions to collect the demographic data of the dentists and also to determine the knowledge and awareness about the bone-loss management during orthodontic treatment. 35 (35.6\%) dentists feels than duration of the orthodontic treatment plays an important role in the bone loss after the orthodontic treatment. $79(80.7 \%)$ of the dentists feels that continuous, interrupted and intermittent forces all together acts together during the orthodontic treatment. $93(94.8 \%)$ dentists are familiar with the fact that bone loss occurs after the orthodontic treatment. Proper guidelines and advice need to be given to the patient prior and after the orthodontic treatment to manage the bone loss after the orthodontic treatment.

Keywords: Orthodontic treatment, beauty of smile, alveolar bone loss, bone-loss management.

Copyright @ 2020: This is an open-access article distributed under the terms of the Creative Commons Attribution license which permits unrestricted use, distribution, and reproduction in any medium for non-commercial use (NonCommercial, or CC-BY-NC) provided the original author and source are credited.

\section{INTRODUCTION}

The process of diagnosis, prevention and correction of the mal-positioned, crowded, over-bite and under-bite teeth and jaw is Orthodontics. Orthodontics is a speciality of dentistry. The orthodontist helps to close the wide gaps, align the tips of the teeth, straighten the crooked teeth, improves the speech, enhances the chewing ability, boosts the life of the gums and teeth, prevents the excessive worn-out of the teeth and corrects the improper bite [1]. The orthodontic treatment includes the use of varied dental devices like headgear, braces and plates to enhance the beauty of smile, improves the speech and the biting ability.

Although the orthodontic treatment is used to straighten the teeth and also improves or enhances the appearance of the teeth and the face but there are some undesirable factors associated with orthodontic treatment like, it can lead to the root resorption and also the loss in bone density during the orthodontic treatment [2]. The previous researchers reported that orthodontic treatment can result in the shortening of the root and also increases the chances of loosening of the teeth [3].
Few of the previous studies also shows that orthodontic treatment is associated with the alveolar bone density loss and that enhances the decrease in the bone density around the treated teeth [4]. The treatment that causes the movement of the teeth and also results in decrease in bone density of the teeth. The loss of bone around the tooth may be temporary or permanent. The temporary loss can be recovered after a period of retention whereas the permanent may lead to the development of tooth resorption.

Its very important for the dentist who are treating patients during the orthodontic treatment to know about the bone loss and the management of the bone loss [5]. If bone loss is not treated properly it may lead to the loosening of the teeth and finally the loss of the teeth. There is a close relationship between the periodontal disease and orthodontic treatment in the adult patients [5]. The orthodontics may sometimes promote the occurrence of the periodontal diseases and sometimes it can reduce the symptoms of various periodontal diseases hence it shares a complicated relationship. 
During an orthodontic treatment a poor oral hygiene is maintained along with abnormal occlusal forces it may result in the formation of the periodontal pockets. The pressure of the braces during the orthodontic treatment can result in the bone loss [6]. However the straightening of the teeth can be beneficial for the jaw in long term as the teeth that are properly aligned can be cleaned easily when compared to overcrowded teeth. Therefore by treating this overcrowded teeth by orthodontic treatment we can reduce the the occurrence of the periodontal diseases that occurs through the gum.

The bone loss during the orthodontic treatment depends upon the the direction, frequency and magnitude of the orthodontic forces acting on the teeth and its anatomical integrity with that of the periodontal tissues. A proper plan need to be considered before orthodontically treating a a patient to reduce the alveolar bone loss. Most of the theories that were studied before show that the exclusive forces and the high hyalinization of the periodontal ligament result in the extensive movement of the cementoclast and osteoclast that may result in the tooth resorption [7].

During the orthodontic treatment there are many risk factors that are associated with severe root resorption like shortened root, traumatized teeth, lack of teeth viability after the root canal treatment [8]. In order to understand the management of the bone loss during the orthodontic treatment the forces need to be studied in terms of their direction of movement of the teeth, duration of Action of forces, type of forces and its magnitude [9]. The bone loss managed by properly maintaining the tissues and caring for them during the orthodontic treatment and the oral hygiene is to be mentioned and evaluated by the dentist and also a proper education need to be given to the patient about the home care. So these are some of the vital factors responsible for the bone loss and its management.

The continuous evaluations of the teeth need to be done by using the radio-graphs and also to carefully examine the oral hygiene for all the success of the orthodontic treatment. Thus the aim of the study is to conduct a cross-sectional study on the dentist of Jizan to determine the knowledge about the bone loss management during the orthodontic treatment.

\section{METHODOLOGY}

RESEARCH INSTRUMENT: The predesigned, pre-tested, and self-administered questionnaire survey was conducted among the Dentists of Jizan practising in Jizan, Saudi Arabia. The dental practitioners of Jizan, Saudi Arabia had to answer the questionnaire to determine their knowledge and awareness about the bone loss management during the orthodontic treatment. This survey was conducted from a period from 2018-2019. The questionnaire was both in Arabic and English language. The survey included questions to collect the demographic data of the dentists and also to determine the knowledge and awareness about the bone-loss management during orthodontic treatment.

About 98 dentists answered the questions of the survey. The inclusion criteria for the study were general dentists belonging to Jizan region and Saudi nationality, and only human beings were considered for this survey. The exclusion factors were any dentists working outside Jizan, Saudi Arabia.

\section{RESULTS}

A total of 98 dentists participated in this study. Among this 98, $42(43 \%)$ were general doctors and 42 $(43 \%)$ were dental interns and $14(14 \%)$ were dental specialists. Majority of the dentists $38(38.7 \%)$ were in the age group below 20 years, followed by $34(34.7 \%)$ were in $21-30$ years of age, $11(11.2 \%)$ were in $31-40$ years age group, $6(6.2 \%)$ were in $41-50$ years age group, $7(7.1 \%)$ were in 51-60 years age group and 2 $(2.0 \%)$ were above 60 years.

About $68(69.3 \%)$ were females and 30 $(30.7 \%)$ were males. $58(59.1 \%)$ had less than 1 year experience, $24(24.4 \%)$ had 2 years' experience, 3 $(3.0 \%)$ have 3 years' experience, $9(9.1 \%)$ have 4 years' experience and $4(4.0 \%)$ have more than 5 years of experience. 
Table-1: Demographic characters

\begin{tabular}{|l|c|c|}
\hline \multicolumn{1}{|c|}{ DEMOGRAPHIC } & FREQUENCY & PERCENTAGE \\
\hline Professional status & & \\
General dentists & 42 & 43 \\
Dental Specialists & 14 & 14 \\
Dental Intern & 0 & 43 \\
None of the above & & 0 \\
\hline Age & 38 & \\
<20 years & 34 & 38.7 \\
21-30 years & 11 & 34.7 \\
31-40 years & 6 & 11.2 \\
41-50 years & 7 & 6.2 \\
51-60 years & 2 & 7.1 \\
$>60$ years & & 2.0 \\
\hline Gender & 68 & 69.3 \\
Female & 30 & 30.7 \\
Male & & \\
\hline Professional Experience & 58 & 59.1 \\
$<1$ year & 24 & 24.4 \\
2 years & 3 & 3.0 \\
3 years & 9 & 9.1 \\
4 years & 4 & 4.0 \\
\hline 5 years & & \\
\hline
\end{tabular}

Table-2: Survey about orthodontic bone loss

\begin{tabular}{|l|c|c|}
\hline \multicolumn{1}{|c|}{ ORTHODONTIC BONE LOSS } & FREQUENCY & PERCENTAGE \\
\hline $\begin{array}{l}\text { According to you, what are the factors } \\
\text { related to bone loss after the orthodontic } \\
\text { treatment }\end{array}$ & & \\
$\bullet \quad$ magnitude of orthodontic force & 16 & \\
$\bullet \quad$ type of force & 11 & 16.5 \\
$\bullet \quad$ direction of tooth movement & 4 & 11.4 \\
$\bullet \quad$ amount of apical movement & 7 & 4.0 \\
$\bullet \quad$ sequence of the arch wire & 15 & 7.1 \\
$\bullet \quad$ type of orthodontic appliance & 1 & 15.3 \\
$\bullet \quad$ duration of orthodontic treatment & 35 & 1.0 \\
$\bullet \quad$ Treatment technique. & 9 & 35.6 \\
\hline $\begin{array}{l}\text { What are the various types of forces that } \\
\text { acts on the tooth during orthodontic } \\
\text { treatment? }\end{array} \quad$ continuous force & & \\
$\bullet \quad$ interrupted force & 10 & \\
$\bullet \quad$ intermittent force & 2 & 10.2 \\
$\bullet \quad$ All of the above & 7 & 2.0 \\
\hline $\begin{array}{l}\text { What do you think should be the golden } \\
\text { rule to be followed when root resorption is } \\
\text { observed? }\end{array}$ & & 7.1 \\
$\bullet \quad$ Stop treatment & & 80.7 \\
$\bullet \quad$ Continue treatment & & \\
\hline
\end{tabular}

Around 35 (35.6\%) dentists feels than duration of the orthodontic treatment plays an important role in the bone loss after the orthodontic treatment, while 16 (16.5\%) feels that magnitude of the orthodontic forces is a factor to bone loss, $15(15.3 \%)$ thinks that sequence of arch wire is the factor responsible for the bone loss after the orthodontic treatment.
$79(80.7 \%)$ of the dentists feels that continuous, interrupted and intermittent forces all together acts together during the orthodontic treatment. $85(86.7 \%)$ thinks that one needs to stop the treatment when root resorption is observed. 
About 93 (94.8\%) dentists are familiar with the fact that bone loss occurs after the orthodontic treatment. $89(90.8 \%)$ thinks that an increase in the intensity of force applied to the tooth during the orthodontic treatment increases the bone resorption of the tooth.

Table-3: Bone loss management

\begin{tabular}{|c|c|c|}
\hline BONE LOSS MANAGEMENT & YES & NO \\
\hline $\begin{array}{l}\text { Are you familiar with the fact that bone loss occurs after the orthodontic } \\
\text { treatment? }\end{array}$ & $\begin{array}{c}93 \\
(94.8 \%) \\
\end{array}$ & $\begin{array}{c}5 \\
(5.2 \%) \\
\end{array}$ \\
\hline $\begin{array}{l}\text { Do you think an increase in the intensity of force applied to the tooth during } \\
\text { orthodontic treatment increases the bone resorption of the tooth? }\end{array}$ & $\begin{array}{c}89 \\
(90.8 \%) \\
\end{array}$ & $\begin{array}{c}9 \\
(9.2 \%)\end{array}$ \\
\hline $\begin{array}{l}\text { Do you think that the root resorption occurs more often during the intrusive } \\
\text { movements of tooth when compared with the extrusive movement? }\end{array}$ & $\begin{array}{c}81 \\
(82.6 \%) \\
\end{array}$ & $\begin{array}{c}17 \\
(17.4 \%) \\
\end{array}$ \\
\hline $\begin{array}{l}\text { Do you think that intermittent forces cause less root resorption than the } \\
\text { continuous forces? }\end{array}$ & $\begin{array}{c}75 \\
(76.5 \%)\end{array}$ & $\begin{array}{c}23 \\
(23.5 \%)\end{array}$ \\
\hline $\begin{array}{l}\text { Do you think that during rotation, resorption lacunae are mostly prevalent in the } \\
\text { middle third of the root? }\end{array}$ & $\begin{array}{c}55 \\
(56.1 \%) \\
\end{array}$ & $\begin{array}{c}43 \\
(43.9 \%) \\
\end{array}$ \\
\hline $\begin{array}{l}\text { Do you think that an increase in apical movement can lead to an increase in } \\
\text { resorption? }\end{array}$ & $\begin{array}{c}82 \\
(83.6 \%) \\
\end{array}$ & $\begin{array}{c}16 \\
(16.4 \%) \\
\end{array}$ \\
\hline $\begin{array}{l}\text { Do you think that there is no relationship between root resorption and the arch } \\
\text { wire sequence? }\end{array}$ & $\begin{array}{c}67 \\
(68.4 \%) \\
\end{array}$ & $\begin{array}{c}31 \\
(31.6 \%) \\
\end{array}$ \\
\hline $\begin{array}{l}\text { Do you think that heavy forces during rapid maxillary expansion might also } \\
\text { induce root resorption in attached premolars and molars? }\end{array}$ & $\begin{array}{c}78 \\
(79.5 \%) \\
\end{array}$ & $\begin{array}{c}20 \\
(20.5 \%) \\
\end{array}$ \\
\hline $\begin{array}{l}\text { Do you think that pressure during implant insertion leads to the lack of } \\
\text { osseointegration? }\end{array}$ & $\begin{array}{c}86 \\
(87.7 \%)\end{array}$ & $\begin{array}{c}12 \\
(12.3 \%)\end{array}$ \\
\hline $\begin{array}{l}\text { Do you think that bone loss is due to functional adaptation of the oral muscles, } \\
\text { wear of the prosthetic material and increase in bone density? }\end{array}$ & $\begin{array}{c}53 \\
(54.1 \%) \\
\end{array}$ & $\begin{array}{c}45 \\
(45.9 \%) \\
\end{array}$ \\
\hline $\begin{array}{l}\text { Do you think that the root canal filling can reduce the bone loss during } \\
\text { orthodontic treatment? }\end{array}$ & $\begin{array}{c}91 \\
(92.8 \%) \\
\end{array}$ & $\begin{array}{c}7 \\
(7.2 \%) \\
\end{array}$ \\
\hline $\begin{array}{l}\text { Do you think that thermoplastic gutta-percha techniques can minimize root } \\
\text { resorption after the orthodontic treatment? }\end{array}$ & $\begin{array}{c}84 \\
(85.7 \%) \\
\end{array}$ & $\begin{array}{c}14 \\
(14.3 \%) \\
\end{array}$ \\
\hline $\begin{array}{l}\text { Do you think that calcium silicate cements offer new opportunities for the } \\
\text { rehabilitation of resorbed teeth? }\end{array}$ & $\begin{array}{c}72 \\
(73.5 \%) \\
\end{array}$ & $\begin{array}{c}26 \\
(26.5 \%) \\
\end{array}$ \\
\hline $\begin{array}{l}\text { Do you think that the prognosis of the treatment of internal resorption, even if } \\
\text { root walls are perforated, is good? }\end{array}$ & $\begin{array}{c}78 \\
(79.5 \%) \\
\end{array}$ & $\begin{array}{c}20 \\
(20.5 \%) \\
\end{array}$ \\
\hline
\end{tabular}

$81(82.6 \%)$ thinks that the root resorption occurs more often during the intrusive movements of tooth when compared with the extrusive movement, 75 $(76.5 \%)$ think that intermittent forces cause less root resorption than the continuous forces, $55(56.1 \%)$ think that during rotation, resorption lacunae are mostly prevalent in the middle third of the root.

Around $82(83.6 \%)$ think that an increase in apical movement can lead to an increase in resorption, $67(68.4 \%)$ think that there is no relationship between root resorption and the arch wire sequence, 78 (79.5\%) think that heavy forces during rapid maxillary expansion might also induce root resorption in attached premolars and molars.

A majority of $86(87.7 \%)$ think that pressure during implant insertion leads to the lack of osseointegration, $53(54.1 \%)$ think that bone loss is due to functional adaptation of the oral muscles, wear of the prosthetic material and increase in bone density.
A total of $91(92.8 \%)$ think that the root canal filling can reduce the bone loss during orthodontic treatment, $84(85.7 \%)$ think that thermoplastic guttapercha techniques can minimize root resorption after the orthodontic treatment, $72(73.5 \%)$ think that calcium silicate cements offer new opportunities for the rehabilitation of resorbed teeth, $78(79.5 \%)$ think that the prognosis of the treatment of internal resorption, even if root walls are perforated, is good.

\section{DISCUSSION}

In the present study the knowledge and Awareness of the dental doctors related to the bone loss management after the orthodontic treatment is studied. The provisions of the cause and effect are seen to be best evident in a cross-sectional study that can only determine the proportion and ratio. According to the previous studies it was found that occurrence of bone loss about $1.2 \mathrm{~mm}$ is seen with the first year of the orthodontic treatment and the bone loss basically occurs during the function wraps adaptation of the jaw muscles and due to the wear and tear of the filling material that is used and the decrease in the bone density $[10,11]$. 
In the previous research that was carried out it was found that the thickness of the bone was gradually decreased among the people of all age groups particularly with the younger patients that have shown greater bone density before the orthodontic treatment had relatively less thickness after the treatment [12]. According to a study it was found that the mandibular inscisors showed increased bone loss after the orthodontic treatment when compared to the other teeth [13]. The maxillary premolars showed a greater extent of bone loss when compared to the other maxillary teeth. The authors in several studies reported that bone loss was mostly seen at apical region. According to most of the previous studies it was shown that an important correlation exists between the treatment dehiscense and the magnitude of change that occurs during the orthodontic treatment. It was also reported that the changes related to the orthodontic treatment were seen to a greater extent in the maxillary jaw bone when compared to the mandibular jawbone.

All the above mentioned important factors need to be considered by the dentists before the treatment is started. Hence the knowledge and awareness of the dental doctors about the bone loss management is of significant importance. To evaluate this, the cross-sectional study was carried out and the results were analysed. It was found that majority of the dental doctors in Jizan had good knowledge and awareness about the bone loss management after the orthodontic treatment.

\section{CONCLUSION}

Bone density can be measured using the computed tomography (CT) and Dental cone beam computed tomography (DCBCT) methods. It was found by many of the dentist that the bone density before the the orthodontic treatment was reduced in the teeth where the orthodontic treatment is been done, but after a period of recovery the bone density can be recovered.

The results of this study recorded that about 42 $(43 \%)$ were general dentists and dental interns, $38(38.7 \%)$ were in the age group below 20 years, 68 $(69.3 \%)$ of all the dentists were females, and 58 $(59.1 \%)$ had less than 1 year of work experience. 35 (35.6\%) dentists feels than duration of the orthodontic treatment plays an important role in the bone loss after the orthodontic treatment. $79(80.7 \%)$ of the dentists feels that continuous, interrupted and intermittent forces all together acts together during the orthodontic treatment. $93(94.8 \%)$ dentists are familiar with the fact that bone loss occurs after the orthodontic treatment.

In order to avoid the loss in bone density around the teeth before, during and after the orthodontic treatment we need to carefully monitor using the dental cone beam computed tomography. 7 to 8 months to recover after the active orthodontic treatment. Basic factors that affect the bone density during the orthodontic treatment maybe Genetics, systemic factors, nutrition, chronological age, dental age, sex, ethnic group, habits like nail biting, bruxism, number of teeth treated, tooth structure, dental trauma, influence of the tooth extraction, type of orthodontic force, duration of orthodontic treatment, removal of the appliance and other factors like tooth vitality.

Like any other treatment orthodontic treatment is also associated with few undesirable Side Effects one of them is bone loss. The knowledge and Awareness of these Side Effects is essential for the orthodontist and also the patient who is undergoing the orthodontic treatment. Proper guidelines and advice need to be given to the patient prior and after the orthodontic treatment to manage the bone loss after the orthodontic treatment.

\section{LIMITATIONS}

This study was carried out among the dental doctors of Jizan, hence we cannot generalize the results of this study globally or all over Saudi Arabia.

\section{ETHICAL CONSIDERATION Compliance with ethical standards}

Ethical approval: This article contains a survey with the evaluation of knowledge and awareness about the bone loss management among the dental doctors in Jizan, Saudi Arabia.

Conflict of interest: All the authors do not have any commercial associations that might pose or create a conflict of interest with information presented in this communication. No intramural or extramural funding supported any aspect of this work.

\section{REFERENCES}

1. Travess, H. (2004). Orthodontics. Part 6: Risks in orthodontic treatment. Br Dent J.196:71-7.

2. Huang, H., Richards, M., Bedair, T.(2013). Effects of orthodontic treatment on human alveolar bone density distribution. Clin Oral Investig, 17:20332040.

3. Rischen, R.J., Breuning, K.H., Bronkhorst, E.M. (2013). Records needed for orthodontic diagnosis and treatment planning: a systematic review. PLoS One, 8:e74186.

4. Han, G., Huang, S., Von, den, Hoff, J.W., Zeng, X., Kuijpers-Jagtman, A.M.(2005). Root resorption after orthodontic intrusion and extrusion: an intraindividual study. Angle Orthod.75:912-18

5. Ma, Z.G., Yang, C., Fang, B. (2015). Three-D imaging of dental alveolar bone change after fixed orthodontic treatment in patients with periodontitis. Int J Clin Exp Med, 8:2385-2391.

6. Brezniak, N. (2002). Orthodontically induced inflammatory root resorption. Part II: The clinical aspects. Angle Orthod,72:180-4 
7. Hartsfield, J.(2004). Genetic factors in external apical root resorption and orthodontic treatment. Crit Rev Oral Biol Med, 15:115-22.

8. Chan, E., Darendeliler, M.A. (2005). Physical properties of root cementum: Part 5. Am J Orthod Dentofacial Orthop, 127:186-95

9. Jimenez-Pellegrin, C., Arana-Chavez, V.E. (2004). Root resorption in human mandibular first premolars after rotation as detected by scanning electron microscopy. Is J Orthod Dentofacial Orthop, 126:178-84.

10. Picanço, P.R.B., Valarelli, F.P., Cançado, R.H., de Freitas, K.M., Picanço, G.V. (2013). Comparison of the changes of alveolar bone thickness in maxillary incisor area in extraction and non- extraction cases: computerized tomography evaluation. Dental Press J Orthod,18:91-8

11. Yared, K.F.G., Zenobio, E.G., Pacheco, W. (2006). Periodontal status of mandibular central incisors after orthodontic proclination in adults. Am J Orthod Dentofacial Orthop, 130:1-8

12. Li, X., Viceconti, M., Cohen, M.C. (2015). Developing CT based computational models of pediatric femurs. J Biomech, 48:2034-2040

13. Dragomir-Daescu, D., Salas, C., Uthamaraj, S. (2015). Quantitative computed tomographybased finite element analysis predictions of femoral strength and stiffness depend on computed tomography settings. J Biomech, 48:153-161. 